\title{
Diagnóstico de la infección por virus papiloma humano en el hombre
}

\author{
Ramón Silva, Daniela León, Priscilla Brebi, Carmen Ili, Juan C. Roa y Raúl Sánchez
}

\begin{abstract}
Universidad de La Frontera, Temuco, Chile.

BIOREN-CEGIN (Centro de Excelencia en Estudios Genéticos Inmunológicos). Laboratorio de Virus Oncológicos en Reproducción (RS, DL, PB, Cl, RS) Departamento Anatomía Patológica. Laboratorio de Patología Molecular (PB, Cl, JCR) Pontificia Universidad Católica de Chile, Santiago, Chile. Facultad de Medicina Departamento de Patología (JCR)

Los autores no poseen conflictos de intereses para la publicación de este artículo.

Financiamiento: Este trabajo fue financiado en parte por Proyecto FONDECYT postdoctorado 3120141, Proyecto Creación de centro de excelencia en estudios genéticos e inmunológicos (CEGIN) 09CN14-5960 y Núcleo de Desarrollo Científico Tecnológico en Biorecursos (BIOREN)

Recibido: 15 de noviembre de 2012 Aceptado: 11 de febrero de 2013

Correspondencia a: Raúl Sánchez Gutiérrez rsanchez@ufro.c

\section{Introducción}

L a infección por virus papiloma humano (VPH) es la infección de transmisión sexual (ITS) más frecuente en el mundo ${ }^{1}$ y el principal agente causal del cáncer cérvico-uterino (CCU), encontrándose en $99,7 \%$ de los casos ${ }^{2}$. El VPH afecta a hombres y mujeres por igual; sin embargo, en hombres principalmente se ha asociado a lesiones como verrugas ano-genitales y a neoplasias intraepiteliales de pene y ano $^{3}$. La infección por VPH en el hombre ha sido considerada como un problema menor y de escasa relevancia. En general se ha catalogado al hombre como vector silencioso de este microorganismo, ya que a pesar de jugar un papel importante en la transmisión del virus, sólo $1 \%$ de ellos experimenta algún signo o síntoma clínico ${ }^{3}$. El objetivo de esta revisión es describir la patogenia de VPH y sus principales técnicas de detección en el hombre.
\end{abstract}

\section{El virus}

El VPH pertenece a la familia Papillomaviridae y al género Papillomavirus ${ }^{4}$. Su contenido genético posee un ADN circular de doble hebra con 7.900 pares de bases, que se encuentra asociado con histonas formando un complejo similar a la cromatina ${ }^{5-9}$. No posee envoltura. Su cápside icosahédrica está compuesta por 72 capsómeros. El genoma de VPH contiene en promedio ocho open reading frame (ORF) importantes que son expresados a través de ARNm policistrónicos, transcritos de una sola hebra de $\mathrm{ADN}^{9}$. Su ADN se puede dividir en tres secciones: una región de control (LCR, long control region) una región temprana $\mathrm{E}$ (early) y una región tardía L (late) $)^{7}$. La región
LCR contiene un centro promotor llamado p97 (en VPH 16) o p105 (en VPH 18) que permite potenciar o silenciar secuencias que regulan la replicación del $\mathrm{ADN}$ mediante el control de la transcripción de los ORF ${ }^{8,9}$. Además esta región contiene la mayor variación genética entre un tipo viral y otro9. Las proteínas E1 y E2 transcritas a partir de la región temprana son responsables de la replicación viral y expresión génica9. La región tardía codifica para las proteínas L1 y L2, componentes de 95 y 5\%, respectivamente, de la cápside viral ${ }^{7.8}$. Las proteínas E6 y E7, productos de la región temprana, son las encargadas de inmortalizar la célula hospedera y del proceso carcinogénico ${ }^{5,7,10}$.

Existen varios géneros para esta familia, de los cuales sólo Alpha-papillomavirus, Beta-papillomavirus y Gamma-papillomavirus infectan humanos ${ }^{4}$. Se han descrito más de 200 tipos de VPH, los cuales tienen tropismo por epitelios escamosos estratificados, infectando piel, mucosa oral y/o del tracto ano-genital ${ }^{7,8}$. Los tipos de VPH cutáneos, entre ellos los tipos 1, 2, 3, 7 y 10, tienen como blanco principalmente manos y pies, formando verrugas típicas de la infección ${ }^{7,8}$. Los VPH que tienen preferencia por tejidos mucosos infectan las células epiteliales basales de la boca, garganta tracto respiratorio o epitelio ano-genital y en cualquiera de ellos VPH podría dar origen a un proceso carcinogénico ${ }^{7}$.

Los VPH transmitidos por vía sexual son aproximadamente 40, los que pueden ser agrupados en VPH de bajo riesgo (BR) y alto riesgo (AR) oncogénico ${ }^{6,7,11}$. Los VPH de BR incluyen los tipos 6, 11, 42, 43 y 44, entre los más frecuentes. De ellos, los más importantes son los tipos 6 y 11 , que producen verrugas genitales tanto en hombres como en mujeres ${ }^{5-7}$. Los VPH de AR son los tipos 16,18 , $31,33,34,35,39,45,51,52,56,58,59,66,68$ y 70 . De 
estos tipos virales, el más importante y más frecuente en el CCU es VPH $16^{5-7}$.

Se estima que la tasa de infección varía entre 1,4 y $25,6 \%$ de la población general, dependiendo de la región, pero las tasas más altas se encuentran en África SubSahara y Sudamérica ${ }^{12}$. También es notoria la frecuencia del tipo viral 16, que en todo el mundo es el prevalente $e^{5,7}$. Además, es evidente que a mayor edad disminuye la prevalencia de infección por $\mathrm{VPH}^{5}$. Esto se debería al clearence o "limpieza" que realiza el sistema inmune y que elimina sistemáticamente los tipos virales, así como las células infectadas ${ }^{6}$.

El VPH es resistente al calor y la desecación, por tanto la infección mediante vías no sexuales, como a través de intercambio de ropas es posible ${ }^{5}$. Además este virus se encuentra en toda la zona genital incluyendo escroto, labios mayores, cuerpo del pene, glande etc.; en consecuencia, el uso de condón no prevendría totalmente la infección por $\mathrm{VPH}^{5,7,13}$.

\section{Patogénesis de la infección por VPH (Figura 1)}

Diferentes estudios han intentado explicar la fisiopatología y modelo de infección por VPH de alto riesgo, siendo descrito principalmente en el epitelio cervical. Durante la actividad sexual se produce un microtrauma lo que permite la entrada de viriones a la capa basal del epitelio cervical, ya que VPH sólo infecta a células del tejido mucoso que puedan proliferar ${ }^{6-9,14}$. Esto ocurre mediante la unión entre receptores celulares y el virus, principalmente heparán sulfato para VPH 16 y $\alpha_{6}$-integrina para VPH $6^{7,8}$. Una vez dentro de la célula hospedera, el ADN viral se replica a medida de que la capa basal se diferencia y progresa a la superficie del epitelio ${ }^{9}$. Mientras el virus se encuentra en la capa basal se mantiene en estado episomal con pocas copias de ADN y utiliza la maquinaria celular para la replicación de su genoma ${ }^{7}$. Cuando la célula se va diferenciando el virus aumenta su tasa de replicación y además comienza a producir las proteínas L1 y L2 relacionadas con la cápsula 9 .

La replicación del ADN viral comienza con la interacción de los factores de transcripción de la célula con la región LCR del virus y los genes virales E6 y E7 son los primeros en ser transcritos 7 . La proteína E6 se une con una proteína celular denominada proteína asociada a E6 (E6AP) que cumple una función de ubiquitina ligasa ${ }^{15}$. E6 aumenta la afinidad de E6AP por p53 promoviendo la rápida degradación de p53, mediante un complejo enzimático de ubiquitinización, lo que inactiva las funciones de p53, entre las que se encuentran: regular el ciclo celular mediante arresto en etapa G1, mediar procesos de apoptosis e intervenir en la reparación del ADN, regular la expresión de ErbB2 y estimular otros genes supresores de tumores como Notch $1^{5,7,10}$. Por otra parte, la proteína E7 viral se puede unir a la forma hipofosforilada de la proteína retinoblastoma $(\mathrm{RB})^{5,7,10}$. Esta unión rompe el complejo entre RB y el factor de transcripción E2F-1, por lo que E2F-1 queda libre y se une a promotores de genes necesarios para que la célula entre en fase $S$ del ciclo celular y así comenzar su transcripción ${ }^{7,8}$.

Sin duda, el principal factor para el desarrollo de las lesiones es la sobre-expresión de las oncoproteínas virales E6 y E7. Luego de la acción de E6 y E7 se produce la transcripción de la proteína E5 que induce un incremento en la actividad de proteínas kinasas, principalmente receptores; por consiguiente, la respuesta celular para los factores de crecimiento y de diferenciación se ve aumentada, dando como resultado una proliferación continua y diferenciación retardada de la célula anfitriona ${ }^{7,14,16}$. El siguiente evento que se presenta es la transcripción de E1 y E2. E1 posee una actividad de helicasa, separando las hebras de ADN y permitiendo la unión del complejo de replicación ${ }^{16}$. La proteína $\mathrm{E} 2$ bloquea la transcripción de E6 y E7, permitiendo que E1 se una al origen de la replicación del virus ${ }^{7,10}$. Esto inicia la replicación del ADN viral en forma extra-cromosomal, en conjunto con la fase $\mathrm{S}$ del ciclo celular. Cuando cesa la transcripción de E6 y E7 debido a la regulación de E2, las proteínas p53 y RB pueden continuar con su función normal. Posteriormente

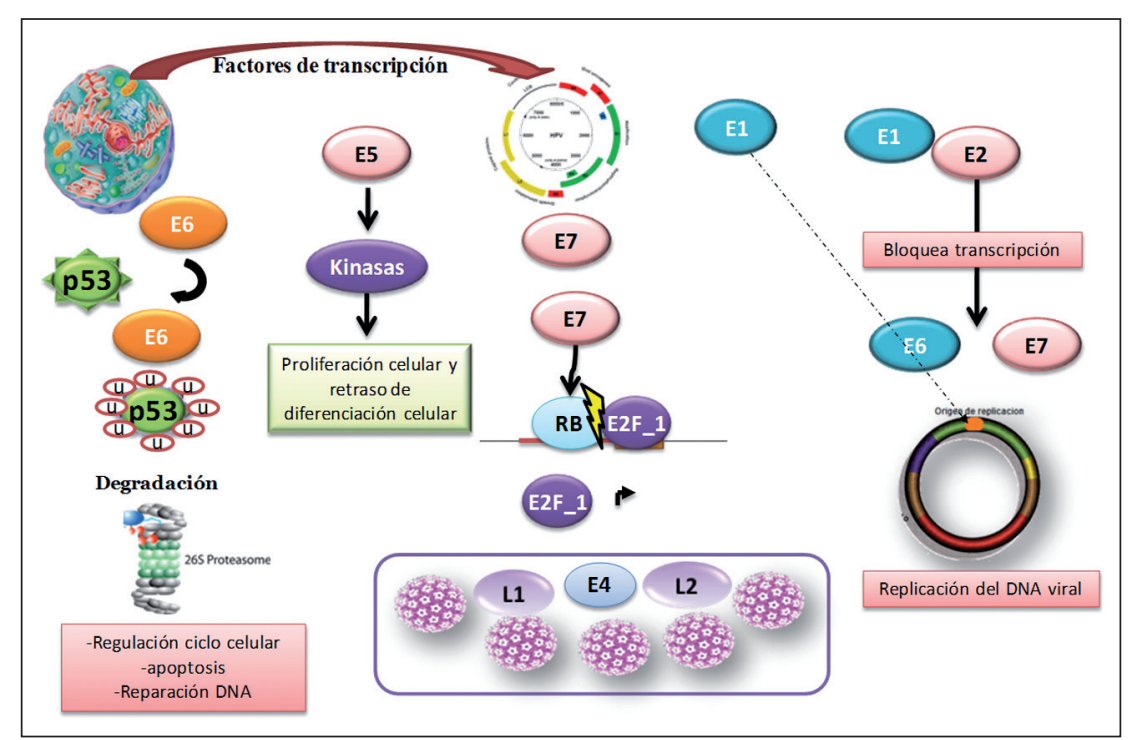

Figura 1. Patogenia de la infección por VPH. Acciones de las distintas proteínas codificadas por VPH. Una vez que las células son infectadas por VPH comienza la replicación del virus gracias a factores de transcripción de la célula hospedera y la proteína E1 viral. E7 se une la proteína retinoblastoma dejando libre al factor de transcripción E2F, lo que permite la activación de genes que aumentan la proliferación celular. La oncoproteína E6 es capaz de inducir la ubiquinización y posterior degradación de p53, lo que conlleva a disminución de la apoptosis mediada por p53. E2 regula la transcripción de las oncoproteínas E6 y E7. La proteína E5 aumenta la acción de las kinasas celulares lo cual promueve la proliferación y disminuye la diferenciación celular. E4 ayuda al ensamblaje de las proteínas de la cápside viral L1 y L2 para el empaquetamiento de los viriones de VPH. 
aparecen las proteínas L1 y L2 pertenecientes a la cápside viral, que con la ayuda de la proteína E4, forman el virión completo, el que es liberado en las capas superiores del epitelio cervical sin producir lisis celular ${ }^{7,8,16}$. Además E4 sería capaz de inducir el colapso de la red de queratina de los queratinocitos, lo que favorecería la liberación de los viriones ${ }^{16}$. La importancia de los tipos virales de AR y el desarrollo de CCU radica en la capacidad de integración del genoma viral en el genoma celular ${ }^{5,7}$ y en la alta afinidad de las proteínas E6 y E7 por las proteínas p53 y RB de la célula, ya que en los VPH de BR la tasa de integración de ADN es menor y la afinidad por las proteínas p53 y RB es baja ${ }^{7}$. Por ejemplo, en E7, un solo aminoácido marca la diferencia de afinidad de ésta con la proteína RB (VPH AR posee un ácido aspártico y VPH BR una glicina $)^{10}$. Los VPH de AR tienen la capacidad de romper el habitual estado circular, específicamente en la región que codifica a E2 e integrar su genoma a la célula hospedera $^{7,10}$. Al romperse la secuencia que codifica para E2 se detiene la retroalimentación negativa que esta proteína tiene sobre la transcripción de E6 y E7, favoreciendo su producción sin un elemento regulatorio, provocando la inmortalización de la célula ${ }^{7,10,16}$. Las altas tasa de proliferación celular y falta de apoptosis comienzan a generar inestabilidad genómica de la célula hospedera lo que conlleva al desarrollo de cáncer?

\section{Infección por VPH en hombres}

Por muchos años la infección por VPH en el hombre fue considerada como un problema menor y de escasa relevancia catalogándolo como el vector silencioso de este microorganismo ${ }^{3}$. Estudios han asociado la infección por VPH en hombre y condilomas genitales, papilomatosis respiratoria recurrente (PRR), neoplasia intraepitelial del pene (NIP), neoplasia intraepitelial anal (NIA), cáncer de pene, cáncer anal, cáncer perianal, cáncer oral, cáncer orofaríngeo, cáncer de próstata y cáncer de uretra ${ }^{17,18}$. Dentro de los más estudiados se encuentra la asociación con cáncer de pene, laringe, cabeza y cuello. Se estima que el VPH es el agente causal de $5 \%$ de los cánceres humanos ${ }^{19}$.

La prevalencia de la infección por VPH en el hombre puede variar de un estudio a otro, lo cual se debe a las técnicas de detección realizada, la zona anatómica de toma de muestra, tipo de muestra y población estudiada, lo que se ejemplifica en la Tabla $1^{18,20-25}$, donde se puntualiza que las diferencias en la frecuencia de detección de VPH en hombres varía de acuerdo a los parámetros mencionados anteriormente, así como del país donde se realizó el estudio.

De la misma manera, la revisión de Dunne y cols., indica prevalencias entre 1,3 y $72,9 \%$, concluyendo que mientras más sitios anatómicos sean muestreados en un mismo estudio, la prevalencia será de $20 \%$ o más ${ }^{26}$.

\section{Técnicas de detección de VPH en hombres}

En la actualidad, el método más utilizado para la detección de VPH en el hombre es la amplificación de ácidos nucleicos utilizando la técnica de reacción de polimerasa en cadena (RPC) y sus diferentes variaciones. La alta sensibilidad de la técnica permite detectar hasta 3,9 copias del ADN viral al comienzo de la reacción ${ }^{27}$. Por otro lado, la utilización de partidores de consenso que amplifican zonas de la región L1 del genoma viral, permiten la detección y posterior tipificación de los diferentes genotipos virales a partir de la amplificación del ADN de una única muestra ${ }^{28}$.

Mientras las etapas para la detección de VPH son similares, los pasos para la tipificación pueden variar. Las principales técnicas utilizan sondas específicas que permiten identificar cada uno de los genotipos virales durante

\begin{tabular}{|c|c|c|c|c|c|}
\hline País & Población de estudio & Tipo de muestra & Método detección de VPH & Frecuencia & Ref. \\
\hline Chile & Estudiantes universitarios & Células exfoliativas del cuerpo del pene y surco coronal & RPC, reverse line blot & $84 \%$ & (20) \\
\hline México & Estudiantes universitarios & Orina & RPC & $50 \%$ & $(21)$ \\
\hline México & Jóvenes militares & $\begin{array}{l}\text { Células exfoliativas del cuerpo del pene, surco coronal, } \\
\text { glande y escroto }\end{array}$ & RPC & $48-61,9 \%$ & $(18,22)$ \\
\hline Brasil & $\begin{array}{l}\text { Estudiantes universitarios } \\
\text { y población general }\end{array}$ & Células exfoliativas del surco coronal, glande y escroto & RPC & $72,3 \%$ & (18) \\
\hline Estados Unidos de América & Estudiantes universitarios & $\begin{array}{l}\text { Células exfoliativas del cuerpo del pene, glande, escroto } \\
\text { y orina }\end{array}$ & RPC & $26 \%$ & $(23)$ \\
\hline Estados Unidos de América & Jóvenes militares & Células exfoliativas del surco coronal, glande y escroto & RPC & $61,3 \%$ & $(18)$ \\
\hline Finlandia & Jóvenes militares & Células exfoliativas del pene & RPC & $9,1 \%$ & (24) \\
\hline Suecia & Jóvenes militares & Orina & RPC & $12 \%$ & (25) \\
\hline
\end{tabular}


la amplificación ${ }^{27}$, como son por ejemplo, el reverse line blot (RLB) ${ }^{28,29}$, el sistema de genotipificación de VPH múltiple $(\mathrm{MPG})^{30}$, entre otros. Uno de los primeros métodos implementados fue el descrito por Gravitt y cols., el cual permite tipificar 27 tipos de VPH (son: 16, 18, 26, $31,33,35,39,45,51,52,55,56,58,59,68,73,82,83,6$, $11,40,42,53,54,57,66$ y 84). Esta metodología utiliza partidores biotinilados de consenso dirigidos a la región L1 del virus, MY09-MY11-HMB0128. Este producto de RPC es posteriormente, desnaturalizado e incubado en una membrana de nylon, a la cual, previamente se le unieron oligonucleotidos específicos para cada uno de los genotipos virales. Una vez hibridizados los productos de RPC, el sistema es revelado utilizando un sistema streptavidina-peroxidasa ${ }^{28}$.

Este método fue modificado para mejorar la sensibilidad y reproducibilidad de los partidores; para ello se desarrolló un nuevo set de oligonucleótidos (PGMY09/ PGMY11 $)^{31}$. Basado en esta técnica, se analizó la prevalencia de VPH en hombres según su comportamiento sexual, agrupándose en los que tenían sexo con hombres (HSH), los que tiene sexo con mujeres (HSM) y los que tenían sexo con mujeres y hombres (HSMH) con una prevalencia de VPH oncogénico por grupo de 29,7\% (HSH), 39,6\% (HSMH) y 30,0\% (HSM) ${ }^{32}$. La detección y tipificación de VPH en hombres asintomáticos americanos, en conjunto la relación de prevalencia de VPH con el uso del condón, demostró una prevalencia de 70,5\%, para VPH en general, mientras que VPH oncogénico y no oncogénico tuvieron una prevalencia de 34 y 19,7\%, respectivamente ${ }^{33}$. En un estudio reciente, la concordancia del tipo de VPH entre parejas heterosexuales, se asoció a distintos factores; por ejemplo, entre parejas que informaron monogamia presentaron una concordancia positiva VPH tipo específico de $19,7 \%{ }^{34}$.

Utilizando una metodología similar, se ha desarrollado un método de tipificación de 37 genotipos de VPH utilizando partidores de consenso dirigidos a la región L1 del virus (GP5+/6+). En general, los métodos de tipificación basados en RLB poseen una alta sensibilidad, son reproducibles y pueden ser validados ${ }^{29}$. Así, en un grupo de hombres asintomáticos, de 20 a 51 años, la prevalencia de VPH fue de $84 \%$ (n: 61). Mediante esta tipificación, los VPH de alto riesgo representaron $35 \%$ del grupo de estudio, siendo VPH 16 el más frecuente (45\%), mientras que los VPH de bajo riesgo se detectaron en $8 \%$ de los sujetos ${ }^{20}$. Por otro lado, la tipificación de VPH en muestras de células de pene determinó que VPH 56 estaba presente en $29 \%$ de los casos y VPH 16 en $25,8 \%{ }^{35}$. En HSH, la prevalencia estimada para el VPH fue de $83,5 \%$ de un total de 109 individuos analizados, del cual 40,7\% presentó más de un genotipo de VPH y 43,6\% de los individuos estudiados presentó al menos un genotipo de alto riesgo. Los genotipos más frecuentes fueron VPH 6 (28,6\%),
VPH $16(24,5 \%)$ y VPH $11(21,0 \%)^{36}$. Asimismo, es posible encontrar la presencia de múltiples tipos de VPH en hombres. En un estudio realizado en Kenya, de un total de 2.702 sujetos estudiados, $51 \%$ fue positivo para algún tipo de VPH, donde $29 \%$ (n: 787) se detectaron múltiples tipos de VPH, siendo el más frecuente VPH 16 (n: 263; $10 \%$ ). Los genotipos más frecuentes dentro del grupo que fue positivo para múltiples tipos de VPH fueron: VPH 16 (n: 196; 25\%), VPH 56 (n: 135; 17\%), VPH 42 (n: 120; 15\%), VPH 67 (n: 117; 15\%), y VPH 52 (n: 116; 15\%). Sin embargo, aquellos individuos positivos solamente para VPH-X (sin determinar) fueron considerados como infectados por un único genotipo, cuando éste podría haber correspondido a diferentes genotipos y por lo tanto haber subestimado el porcentaje de infecciones múltiples en el grupo analizado ${ }^{37}$.

La captura híbrida (Hybrid Capture ${ }^{\circledR} 2$ de DIGENE) es uno de los métodos más utilizados para detectar VPH en muestras de citología cérvico-uterina ${ }^{38}$. Esta técnica utiliza un pool de oligosondas de ARN complementarias a algunos genotipos de VPH, formando una unión única entre ADN-ARN que es reconocida por un anticuerpo específico $^{38}$. Este método cuenta con la aprobación de la FDA (Food and Drug Administration) de E.U.A., para uso clínico y se utiliza como método de tamizaje, aunque sólo permite discriminar entre tipos virales de alto y bajo riesgo oncogénico, sin informar sobre el genotipo viral específ$\mathrm{co}^{38}$. Utilizando esta metodología se evaluó la incidencia del VPH en hombres asintomáticos, para lo cual la muestra fue tomada por los mismos sujetos de estudio, usando una tórula húmeda que fue frotada por el glande, surco coronal y zona interior del prepucio. La tasa de detección fue de $8 \%$ (n: 150) en hombres de entre 18 a 34 años $^{39}$. Con la misma metodología se evaluó la presencia de VPH en hombres heterosexuales, cuyas parejas eran positivas para VPH, obteniendo $70 \%$ de casos positivos (n: 50). Las muestras analizadas para VPH correspondían a seis diferentes áreas ano-genitales: glande, superficie interna del prepucio, uretra distal, superficie externa del prepucio, escroto y ano, cada una de ellas procesada y analizada de forma independiente para la detección de $\mathrm{VPH}^{40}$.

Otra de las técnicas es NucliSENS EasyQ VPH (BioMérieux), basada en la tecnología de amplificación isotérmica de ácidos nucleicos (NASBA) y cuyo objetivo es la detección de los ARNm que codifican para las oncoproteinas E6 y E7 de los virus VPH de alto riesgo. Las principales ventajas de esta metodología son la utilización de una temperatura constante para la amplificación, por lo que no se requiere de termociclador, y la rapidez del ensayo. La capacidad diagnóstica del NucliSENS EasyQ VPH utilizando muestras anales de parejas de HSH determinó que éste posee una sensibilidad mayor en comparación a métodos de amplificación basados en RPC ${ }^{41}$. En la Tabla 2 se comparan los métodos analizados anteriormente. 


\begin{tabular}{|c|c|c|c|c|}
\hline Nombre & Metodología & Resultado & Sensibilidad & Cita \\
\hline Captura híbrida 2 & $\begin{array}{l}\text { ADN incubado con sondas específicas de ARN. Los comple- } \\
\text { jos ADN-ARN son detectados por anticuerpos específicos } \\
\text { para AR-VPH y LR-VPH }\end{array}$ & Detección según AR-VPH y LR-VPH & $63-100 \%$ & (38) \\
\hline RPC seguida de reverse line blot (RLB) & $\begin{array}{l}\text { Amplificación del gen L1 viral. Posterior genotipificación } \\
\text { mediante sondas complementarias a cada genotipo }\end{array}$ & $\begin{array}{l}\text { Genotipificación de cada tipo viral } \\
\text { en sólo una reacción }\end{array}$ & 10-100 copias de ADN & $(28,29)$ \\
\hline NucliSENS EasyQ & Está basado en NASBA y detecta ARNm de E6 y E7 & $\begin{array}{l}\text { Detección del ARNm de las onco- } \\
\text { proteínas virales E6 y E7 }\end{array}$ & $95,3 \%$ & $(41)$ \\
\hline
\end{tabular}

\section{Tipos de muestras para la detección de VPH} en hombres

Una de las consideraciones más importantes para la detección del VPH en el hombre ha sido el sitio anatómico para la obtención de la muestra, debido a que existe una gran variabilidad en la incidencia de este virus según el sitio donde se obtenga la muestra (Figura 2). Las muestras obtenidas de uretra y semen son las que presentan menor positividad para la detección de VPH. Las muestras más recurrentes se obtienen mediante la frotación y rotación de tórulas humedecidas en el glande, corona y surco coronal, prepucio (zona interna y externa), eje del pene, uretra, escroto y ano ${ }^{42}$. Asimismo, las muestras de orina han sido ampliamente estudiadas por sus ventajas como método de muestreo; sin embargo, los resultados no han sido totalmente satisfactorios ${ }^{43}$. Además, se han realizado estudios para la identificación de VPH en muestras de semen, por las implicancias que el VPH podría tener sobre la funcionalidad, la concentración, movilidad y viabilidad de los espermatozoides ${ }^{44}$.

Debido a que un mismo individuo puede ser positivo para VPH en varios sitios anatómicos al mismo tiempo, uno de los desafíos es determinar la combinación de muestras más representativas y accesibles que no alteren la prevalencia estimada y que, a su vez, tengan aceptación entre los hombres. La evaluación del sitio anatómico más

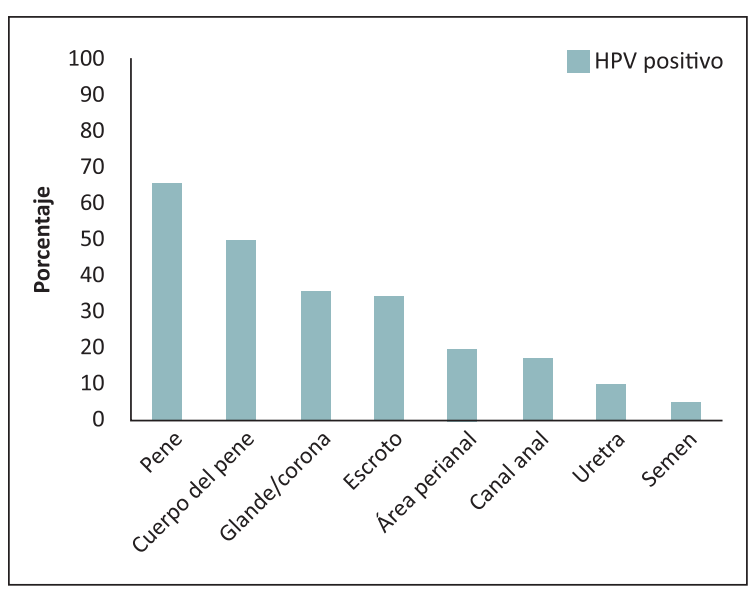

adecuada para la detección de VPH en hombres heterosexuales demostró una mayor prevalencia en muestras del eje del pene $(49,9 \%)$ seguido por el glande/surco coronal $(35,8 \%)$, y los sitios con menor detección fueron la uretra $(10,1 \%)$ y el semen $(5,3 \%)$, con una incidencia total estimada de $65,4 \%{ }^{42}$. Estos resultados concuerdan con estudios previos, donde la mayor presencia de VPH se encuentra en el eje del pene ${ }^{45}$. Además, es importante destacar las diferencias en la positividad para VPH entre las muestras perianales y anales de hombres heterosexuales y HSH, donde las muestras de estas zonas en HSH fueron $32,8 \%$ positivas, una proporción dos veces superior a la de hombres heterosexuales en el mismo estudio ${ }^{46}$. A su vez, en un estudio reciente se han determinado prevalencias de $12,2 \%$ entre heterosexuales y $47,2 \%$ entre HSH para la misma zona ${ }^{47}$. También se ha descrito la prevalencia de más de un tipo de VPH infectando un mismo individuo. Los diferentes genotipos son comúnmente detectados en muestras del eje del pene, glande y corona ${ }^{48}$.

La orina como muestra para la detección de VPH ha sido objeto de un gran número de estudios, debido a las ventajas como método no invasor, de uso frecuente y además que el mismo sujeto de estudio/paciente puede tomar la muestra. Por otro lado, permitiría la obtención y análisis de un gran número de muestras. Uno de los problemas en este tipo de muestras es que las concentraciones de ADN obtenidas de la orina no son constantes durante la micción. Para la mayor parte de los individuos la primera micción es la que contiene la mayor concentración de $\mathrm{ADN}^{49}$. Además, las muestras de orina de hombres poseen menores concentraciones de $\mathrm{ADN}$ que la muestras de orina de mujeres ${ }^{50}$.

\section{Comentarios finales y direcciones futuras}

La detección de la infección de transmisión sexual por VPH en el hombre debe ser considerada de alta prioridad, debido a que la población masculina tiene un rol como vector y reservorio del virus, aunque en los últimos años VPH se ha encontrado presente en neoplasias del aparato reproductor masculino y en otros cánceres (anal, oral, etc). Por ello es de gran relevancia realizar los estudios poblacionales de prevalencia de VPH en hombres. Para estos futuros estudios deberá tenerse en cuenta el uso de 


\section{Infectología al Día}

muestras de varias zonas anatómicas, ya que el análisis de todas en conjunto entregará estimaciones certeras de la prevalencia de VPH en el hombre. Además, debido a que técnicas diagnósticas presentan alto grado de correlación, su elección depende de la sensibilidad requerida y el equipamiento disponible.

Las técnicas de detección y genotipificación de VPH en la actualidad se basan, principalmente, en la amplificación del genoma del virus mediante RPC, para posteriormente desarrollar un método complementario que permita discriminar, ya sea, los grupos de VPH de alto o bajo riesgo, o los genotipos individuales. En nuestra experiencia, en la detección de VPH se ha utilizado RPC seguida de diversas metodologías. Sin embargo, la técnica más sensible utilizada en nuestro laboratorio es reverse line blot. Una ventaja que posee esta técnica, es que en una sola reacción es capaz de detectar hasta 40 genotipos virales en 40 muestras al mismo tiempo, lo cual no ocurre con otras metodologías. Además un mismo ensayo puede determinar infecciones múltiples, sin dificultad en la lectura e interpretación.

La determinación de las prevalencias de los diferentes genotipos VPH es importante ya que, si bien, los VPH 16 y 18 son los principales responsables de la aparición de neoplasias de alto grado, el porcentaje restante puede variar según cada población, lo cual también influye en las potenciales estrategias de vacunación.

Por otro lado, en hombres es necesario conocer el grado de persistencia del virus. En la mujer la persistencia del VPH es de aproximadamente 10\%. Este dato es impor- tante para poder realizar seguimiento a la población de más riesgo y que no esté vacunada, como es la de $\mathrm{HSH}$ por el incremento sostenido de la NIA, cuya progresión es similar a la de CCU en la mujer.

En los últimos años se ha demostrado que la infección por VPH en el hombre puede causar diversas patologías en estos individuos, así como también en sus parejas sexuales. Por ello cobra relevancia la necesidad de la detección y genotipificación de VPH en población masculina, para instaurar programas de prevención de la transmisión del virus.

\section{Resumen}

El virus papiloma humano (VPH) corresponde a la infección de transmisión sexual (ITS) más frecuente en el mundo, afectando a hombres y mujeres por igual. En hombres, el VPH ha sido asociado principalmente a lesiones como verrugas ano-genitales y en los últimos años a neoplasias intraepiteliales de pene y ano. La prevalencia de VPH en el hombre es muy variada, dependiendo del tipo de muestra y las técnicas de detección. Las muestras celulares del cuerpo del pene, glande, prepucio, surco coronal, orina y semen han sido las más utilizadas y su detección se realiza habitualmente con técnicas de reverse line blot (RLB) y captura híbrida $(\mathrm{CH})$. Dado a que las mayores tasas de infección se encuentran en África y Latinoamérica, esta revisión tiene como objetivo describir la patogenia de VPH y sus principales técnicas de detección en el hombre.

\section{Referencias bibliográficas}

1.- Dunne E F, Nielson C M, Stone K M, Markowitz L E, Giuliano A R. Prevalence of HPV infection among men: A systematic review of the literature. J Infect Dis 2006; 194 (8): 1044-57.

2.- Walboomers J, Jacobs M, Manos M, Bosch F, Kummer J, Shah K, et al. Human papillomavirus is a necessary cause of invasive cervical cancer worldwide. J Pathol 1999; 189 (1): 12-9.

3.- Partridge J M, Koutsky L a. Genital human papillomavirus infection in men. Lancet Infect Dis 2006; 6 (1): 21-31.

4.- Bernard H U. The clinical importance of the nomenclature, evolution and taxonomy of human papillomaviruses. J Clin Virol 2005; 32: S1-S6.

5.- Ault K. Epidemiology and natural history of human papillomavirus infections in the female genital tract. Infect Dis Obstet Gynecol 2006; Suppl: 047.

6.- Chan J, Berek J. Impact of the human papilloma vaccine on cervical cancer.
J Clin Oncol 2007; 25 (20): 2975-82.

7.- Burd E. Human papillomavirus and cervical cancer. Clin Microbiol Rev 2003; 16 (1): 1-17.

8.- Jung W, Chun T, Sul D, Hwang K, Kang H, Lee D, et al. Strategies against human papillomavirus infection and cervical cancer. J Microbiol 2004; 42 (4): 255-66.

9.- Longworth M, Laimins L. Pathogenesis of human papillomaviruses in differentiating epithelia. Microbiol Mol Biol Rev 2004; 68 (2): 362-72.

10.- Janicek M, Averette H. Cervical cancer: prevention, diagnosis, and therapeutics. CA Cancer J Clin 2001; 51 (2): 92-114.

11.- Clifford G, Smith J, Plummer M, Muñoz N, Franceschi S. Human papillomavirus types in invasive cervical cancer worldwide: a metaanalysis. Br J Cancer 2003; 88 (1): 63-73.

12.- Clifford G, Gallus S, Herrero R, Muñoz N, Snijders P, Vaccarella S, et al. Worldwide distribution of human papillomavirus types in cytologically normal women in the International Agency for Research on Cancer HPV prevalence surveys: a pooled analysis. Lancet. 2005; 366 (9490): 991-8.
13.- Weaver B, Feng Q, Holmes K, Kiviat N, Lee S, Meyer C, et al. Evaluation of genital sites and sampling techniques for detection of human papillomavirus DNA in men. J Infect Dis 2004; 189(4): 677-85.

14.- zur Hausen H. Papillomaviruses and cancer: from basic studies to clinical application. Nat Rev Cancer 2002; 2 (5): 342-50.

15.- Narisawa-Saito M, Kiyono T. Basic mechanisms of high-risk human papillomavirus-induced carcinogenesis: roles of E6 and E7 proteins. Cancer Sci 2007; 98 (10): 1505-11.

16.- Motoyama S, Ladines-Llave C, Villanueva S L, Maruo T. The role of human papilloma virus in the molecular biology of cervical carcinogenesis. Kobe J Med Sci 2004; 50 (1-2): 9-19.

17.- Petersen I, Klein F. HPV in non-gynecological tumors. Der Pathologe 2008; 29 Suppl 2: 118-22.

18.- Giuliano A R, Lazcano-Ponce E, Villa L L, Flores R, Salmeron J, Lee J-H, et al. The human papillomavirus infection in men study: human papillomavirus prevalence and type distribution among men residing in 
Brazil, Mexico, and the United States. Cancer Epidemiol Biomarkers Prev 2008; 17 (8): 2036-43.

19.- de Martel C, Ferlay J, Franceschi S, Vignat J, Bray F, Forman D, et al. Global burden of cancers attributable to infections in 2008: a review and synthetic analysis. Lancet Oncol 2008; 13 (6): 607-15.

20.- Guzmán P, Ili C, Rifo P, Briceño G, Araya J, Villaseca M, et al. Prevalence of human papillomavirus genital infection among male university students. Rev Med Chile 2008; 136 (11): 1381-9.

21.- Lazcano-Ponce E, Herrero R, Hernández-Ávila M, Salmerón J, Leyva A, Meijer CJ, et al. High prevalence of human papillomavirus infection in Mexican males: comparative study of penileurethral swabs and urine samples. Sex Transm Dis 2001; 28 (5): 277-80.

22.- Lajous M, Mueller N, Cruz-Valdéz A, Aguilar LV, Franceschi S, Hernández-Avila M, et al. Determinants of prevalence, acquisition, and persistence of human papillomavirus in healthy Mexican military men. Cancer Epidemiol Biomarkers Prev 2005; 14 (7): 1710-6.

23.- Partridge J M, Hughes J P, Feng Q, Winer R L, Weaver B A, Xi L-F, et al. Genital human papillomavirus infection in men: incidence and risk factors in a cohort of university students. J Infect Dis 2007; 196(8): 1128-36.

24.- Hippeläinen M, Syrjänen S, Koskela H, Pulkkinen J, Saarikoski S, Syrjänen K. Prevalence and risk factors of genital human papillomavirus (HPV) infections in healthy males: a study on Finnish conscripts. Sex Transm Dis 1993; 20 (6): 321-8.

25.- Forslund O, Hansson B G, Rymark P, Bjerre B. Human papillomavirus DNA in urine samples compared with that in simultaneously collected urethra and cervix samples. J Clin Microbiol 1993; 31(8): 1975-9.

26.- Dunne E F, Nielson C M, Stone K M, Markowitz L E, Giuliano A R. Prevalence of HPV infection among men: A systematic review of the literature. J Infect Dis 2006; 194(8): 1044-57.

27.- Kocjan B J, Poljak M, Seme K. Universal ProbeLibrary based real-time PCR assay for detection and confirmation of human papillomavirus genotype 52 infections. J Virol Methods 2010; 163 (2): 492-4.

28.- Gravitt P E, Peyton C L, Apple R J, Wheeler C M. Genotyping of 27 human papillomavirus types by using $\mathrm{L} 1$ consensus PCR products by a single-hybridization, reverse line blot detection method. J Clin Microbiol 1998; 36 (10): 3020-7.

29.- van den Brule A J C, Pol R, Fransen-Daalmeijer N, Schouls L M, Meijer C J L M, Snijders P J F. GP5+ / 6+ PCR followed by reverse line blot analysis enables rapid and high-throughput identification of human papillomavirus genotypes. J Clin Microbiol 2002; 40 (3): 779-87.

30.- Schmitt M, Bravo I G, Snijders P J F, Pawlita M, Waterboer T, Gissmann L. Bead-based multiplex genotyping of human papillomaviruses bead-based multiplex genotyping of human papillomaviruses. J Clin Microbiol 2006; 44 (2): 504-12.

31.- Gravitt P E, Peyton C L, Alessi T Q, Wheeler C M, Hildesheim A, Schiffman M H, et al. Improved amplification of genital human papillomaviruses. J Clin Microbiol 2000; 38 (1): 357-61.

32.- Nyitray A G, da Silva R J, Baggio M L, Lu B, Smith D, Abrahamsen M, et al. The prevalence of genital HPV and factors associated with oncogenic HPV among men having sex with men and men having sex with women and men: the HIM study. Sex Transm Dis 2011; 38 (10): 932-40.

33.- Repp K K, Nielson C M, Fu R, Schafer S, Lazcano-Ponce E, Salmerón J, et al. Male human papillomavirus prevalence and association with condom use in Brazil, Mexico, and the United States. J Infect Dis 2012; 205 (8): 1287-93.

34.- Nyitray AG, Menezes L, Lu B, Lin H-Y, Smith D, Abrahamsen M, et al. Genital human papillomavirus (HPV) concordance in heterosexual couples. J Infect Dis 2012; 206 (2): 202-11.

35.- Backes D M, Bleeker M C G, Meijer C J, Hudgens M G, Agot K, Bailey R C, et al. Male circumcision is associated with a lower prevalence of human papillomavirus-associated penile lesions among Kenyan men. Int J Cancer 2012; 130 (8): 1888-97.

36.- Pando M A, Balán I C, Marone R, Dolezal C, Leu C-S, Squiquera L, et al. HIV and other sexually transmitted infections among men who have sex with men recruited by RDS in Buenos Aires, Argentina: high HIV and HPV infection. PloS one 2012; 7 (6): e39834.

37.- Rositch A F, Poole C, Hudgens M G, Agot K, Nyagaya E, Moses S, et al. Multiple human papillomavirus infections and type competition in men. J Infect Dis 2012; 205 (1): 72-81.

38.- Lörincz A T, Richart R M. Human papillomavirus DNA testing as an adjunct to cytology in cervical screening programs. Arch Pathol \& Lab Med 2003; 127 (8): 959-68.

39.- Takahashi S, Takeyama K, Miyamoto S, Ichihara K, Maeda T, Kunishima Y, et al. Incidence of sexually transmitted infections in asymptomatic healthy young Japanese men. J Infect Chemother 2005; 11 (6): 270-3.

40.- Nicolau S M, Camargo C G C, Stávale J N, Castelo A, Dôres G B, Lörincz A, et al. Human papillomavirus DNA detection in male sexual partners of women with genital human papillomavirus infection. Urology 2005; 65 (2): 251-5.

41.- Silling S, Kreuter A, Hellmich M, Swoboda J, Pfister H, Wieland U. Human papillomavirus oncogene mRNA testing for the detection of anal dysplasia in HIVpositive men who have sex with men. J Clin Virol 2012; 53 (4): 325-31.

42.- Giuliano A R, Nielson C M, Flores R, Dunne E F, Abrahamsen M, Papenfuss M R, et al. The optimal anatomic sites for sampling heterosexual men for human papillomavirus (HPV) detection: the HPV detection in men study. J Infect Dis 2007; 196 (8): 1146-52.

43.- Vorsters A, Micalessi I, Bilcke J, Ieven M, Bogers J, Van Damme P. Detection of human papillomavirus DNA in urine. A review of the literature. Eur J Clin Microbiol Infect Dis 2012; 31 (5): 627-40.

44.- Kaspersen M D, Larsen P B, Ingerslev H J, Fedder J, Petersen G B, Bonde J, et al. Identification of multiple HPV types on spermatozoa from human sperm donors. PloS one 2011; 6 (3): e18095.

45.- Hernández B Y, Mcduffie K, Goodman M T, Thompson P, Zhu X, Wong W, et al. Comparison of physician-and self-collected genital specimens for detection of human papillomavirus in men comparison of physicianand self-collected genital specimens for detection of human papillomavirus in men. $\mathrm{J}$ Clin Mcrobiol 2006; 44 (2): 512-7.

46.- van der Snoek E M, Niesters H G M, Mulder P G H, van Doornum G J J, Osterhaus A D M E, van der Meijden W I. Human papillomavirus infection in men who have sex with men participating in a Dutch gay-cohort study. Sex Transm Dis 2003; 30 (8): 639-44.

47.- Nyitray A G, Carvalho da Silva R J, Baggio M L, Lu B, Smith D, Abrahamsen M, et al. Age-specific prevalence of and risk factors for anal human papillomavirus (HPV) among men who have sex with women and men who have sex with men: the HPV in men (HIM) study. J Infect Dis 2011; 203 (1): 49-57.

48.- Nielson C M, Flores R, Harris R B, Abrahamsen M, Papenfuss M R, Dunne E F, et al. Human papillomavirus prevalence and type distribution in male anogenital sites and semen. Cancer Epidemiol Biomarkers Prev 2007; 16 (6): 1107-14.

49.- Johnson D J, Calderaro A C, Roberts K A. Variation in nuclear DNA concentrations during urination. J Forensic Sci 2007; 52 (1): 110-3.

50.- Bissett S L, Howell-Jones R, Swift C, Silva N D, Biscornet L, Parry J V, et al. Human papillomavirus genotype detection and viral load in paired genital and urine samples from both females and males. J Med Virol 2011; 83 (10): 1744-51. 